\title{
Adaptation of accounting in agribusiness risk management system
}

\author{
Vera Eremenko ${ }^{1}$, Petr Shumilin ${ }^{1, *}$, Elena Shamkina $^{1}$, Vera Shumilina ${ }^{1}$, Tatiana \\ Makartsova $^{1}$, Anastasia Kravchenko ${ }^{1}$, Olga Evsyukova ${ }^{1}$, Anna Filippova ${ }^{1}$, and Dmitry \\ Yatsuk $^{1}$ \\ ${ }^{1}$ Don State Technical University, Gagarina Sq., 1, Rostov-on-Don, Russia
}

\begin{abstract}
The problem of generating relevant accounting information that reflects the risks of agribusiness and its application for management decisions is presented. Maintaining sustainable development dynamics requires the construction of such a risk management system that could timely and adequately respond to the challenges presented to the agricultural sector. In this paper, directions for the adaptation of accounting in the risk management system are developed, and guidelines for organizing accounting in the adaptation process are given.
\end{abstract}

\section{Introduction}

In the economy of any country, agribusiness is a special industry that is associated with many sectors of the economy. However, it is directly dependent on processes of a natural, climatic, and geographical nature. In the national economy, a developed agribusiness determines the level of food security of the country. The functioning of agricultural enterprises is subject to various types of risks. "Modern science characterizes the concept of "post-industrial society" as a "risk society", since risk and uncertainty are present in all areas of human activity, which leads to the need for ongoing management of economic processes" [1].

\section{Materials and methods}

Maintaining sustainable development dynamics requires the construction of such a risk management system that could respond in a timely and adequate manner to the challenges presented to the agricultural sector [2,3,4]. It seems necessary to consider and systematize the totality of the risk impact on sustainable business development, analyze the accounting capabilities of agricultural enterprises to reflect information about risks and assess their impact on the enterprise microenvironment, and develop ways to adapt accounting for risk management. Figure 1 shows the types of risks affecting agricultural enterprises. It should be noted that the range of risks is wider than in other sectors of the economy and includes

\footnotetext{
Corresponding author: petr_shumilin_ml@mail.ru
} 
such specific positions as natural, associated with drought, heavy rains, various forms of natural hazards, viral diseases of animals and plant pests $[5,6,7]$.

Figure 2 illustrates the accounting and economic characteristics of varieties of risks that affect the livelihoods of the agricultural system.

The purpose of this paper is to develop proposals for the adaptation of accounting for risk management in the risk management system at agricultural enterprises. During the writing of this paper, the following tasks are solved:

- to comprehensively consider the organization of accounting in agribusiness and information opportunities to reflect risks;

- to determine the direction for adaptation of accounting;

- to formulate the principles of adaptation;

- to give suggestions on the methodology for accounting risks of the agricultural sector.

In the modern agribusiness, the organization of accounting has several disadvantages that do not allow reflecting and assessing risks. Risk management is divorced from the accounting system and is implemented separately by calculating the likelihood of a negative impact on the industrial and economic activities of agricultural enterprises. Domestic accounting is focused on the chart of accounts approved by Order of the Ministry of Finance No. 94n dated October 31, 2000 N 94n, which does not provide methods for accounting for risk situations. The fact is that domestic accounting is focused on the reflection of already completed operations of economic activity, and its information is related to the past period of time. The balance sheet is a compilation of accounting information for the past period and lags behind the current moment, which is saturated with economic events and is in the flow of changes.

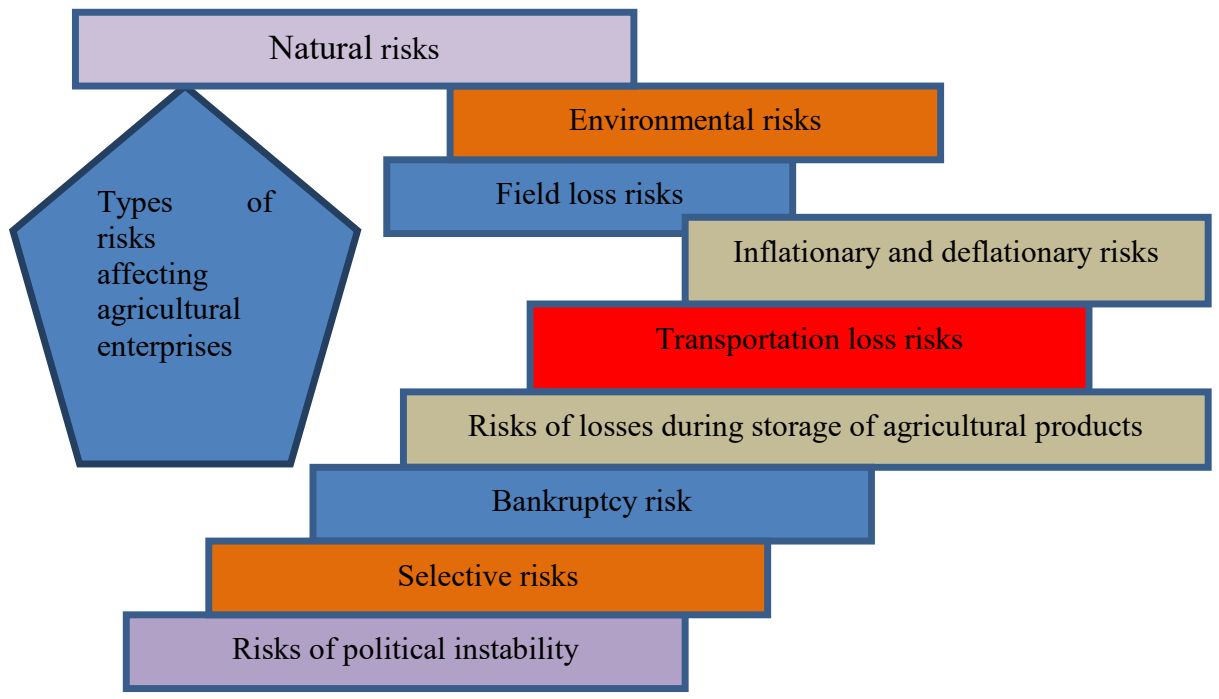

Fig. 1. Types of risks affecting agricultural enterprises.

To solve the problem of adaptation of accounting, the formation of its ability to be applicable as a methodological basis and tool for managing and protecting against risks and risk situations at agricultural enterprises, we have chosen the following areas, which allow realizing the goals and objectives of this study:

- overcoming the conceptual limitations of accounting [8], which consists in using a limited number of its types, in particular, the usual financial accounting based on the chart of accounts referred to in this paper, by applying such a promising type of accounting as 
strategic accounting based on the collection and synthesis of information on environmental factors;

- overcoming the functional limitations of the traditional accounting system [9], which implements the traditional set of functions, such as control, ensuring the preservation of property, informational, analytical, feedback, by adding a prognostic function;

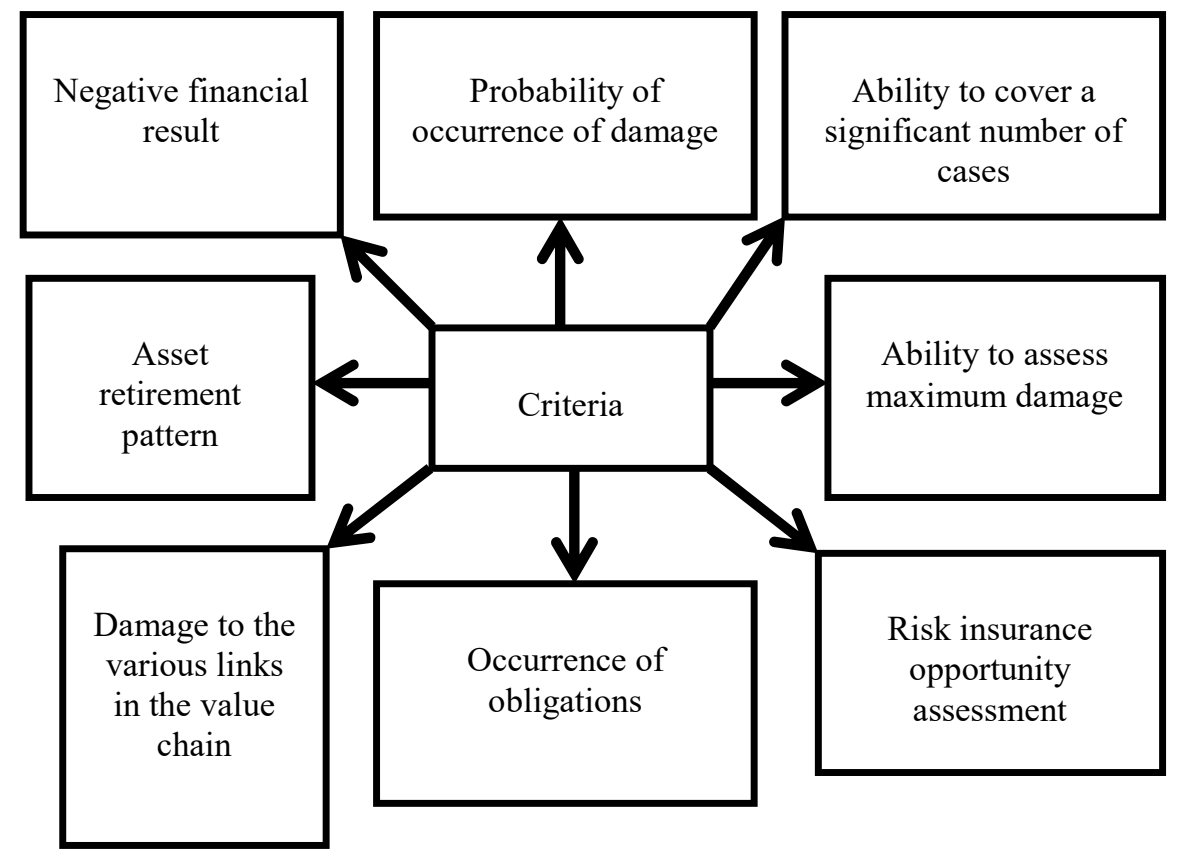

Fig. 2. Accounting and economic risk characteristics.

- expanding the time parameters of the functioning of the accounting system [10] focused on the registration of past economic events, and providing reporting information on the past, focusing accounting on the assessment and reflection of future, estimated economic events that may occur with a certain probability and affect the value of assets and the capital of the agricultural enterprise, by increasing the qualimetric dimension of the used chart of accounts;

- enrichment of the methodological basis of the traditional system that is widespread among agribusiness enterprises, the use of an engineering approach to the formation of accounting information through the use of accounting and engineering tools [11]. "Accounting engineering covers such issues as economic situations, property, innovation, investment, solvency, financial situation, risks, and the reserve system of enterprises. It enables enterprises to effectively respond to changes in the economy, adapting existing ones for these purposes or developing new operational schemes and accounting tools." [12];

- the organizational direction of adaptation is associated with the formation of risk management in agribusiness, integrated with the accounting system, which allows assessing the hedged potential of the management object. "The hedged potential is the cost, taking into account the created aggregates of the reserve system. It is represented by two indicators: hedged carrying capacity - net assets, taking into account aggregates of the reserve system in the balance sheet valuation; hedged market potential - net liabilities, taking into account aggregates of the reserve system in the market valuation." [13].

The process of adaptation of accounting should be based on the following principles. Firstly, the principle of integrity, which consists in the fact that accounting and risk 
management should be a holistic system in which decision-makers rely on indicators generated on the basis of accounting information. Secondly, the principle of flexibility should be implemented, which means that accounting has the ability to adapt to the needs of risk management. This principle is implemented in the ability to configure the risk interface for collecting primary data, in the possibility of opening new analytical positions in a structured work plan of accounts, in the ability to configure the system of indicators, their limit values. Thirdly, the adaptation of accounting should be based on the principle of relevance, which consists in the fact that the generated information should be useful for risk management and focus on a decision support system.

Guidelines for the adaptation of accounting in the risk management system are the implementation of a set of measures aimed at creating a flexible system for generating economically useful information for making management decisions.

The most important adaptation measure is the creation of a risk interface of the accounting system that allows identification of risk situations, their assessment in terms of the likelihood of negative consequences, registration, reflection of protective measures in the current assessment, generation of information on the consequences of risk situations with the aim of their further analysis.

The next adaptation method, in our opinion, is the creation of a risk module for a structured work plan of accounts allowing accounting for the risk exposure at all stages of the business process, which includes capital investment in fixed assets and intangible assets subject to various operational risks, all stages of the production process, accumulating costs for articles and elements, depending on the industry characteristics of agribusiness, which may result in losses from specific risks such as crop failure, pests and plant diseases, animals and poultry epidemics, storage of finished products where there is a risk of loss if the terms and conditions of storage are violated, and also sales of finished products associated with transportation and possible losses during it. Also, the risk module should be able to take into account macroeconomic risks associated, for example, with fluctuations in the prices of finished products. Market management conditions are associated with the impact of such situations as the crisis of overproduction, when at the harvesting stage, its high supply in the market is detected, which causes a drop in sales prices. Agribusiness accounting is adapting to the need to assess agribusiness revenue, taking into account the risks of price fluctuations and possible additional storage costs, with a risk module reflected in the accounts.

The adaptation of accounting to the need to operate with integrated accounting objects, such as situational risk management objects, is a qualimetric opportunity to record a set of business transactions that have a time duration, interconnected by a common goal and having the risk of not achieving the set goal. For example, the acquisition of a property complex of agricultural production, which includes agricultural land, buildings and structures, agricultural machinery can be considered as an investment in a property complex. In this case, the acquisition can be taken into account both objectively and as a whole in the form of a property complex. For objective statement, financial accounting will be used. To reflect the property complex, a management accounting interface must be created that also allows reflecting the risks and results of this investment.

\section{Results and discussion}

The organization of accounting in the risk management system should be based on an engineering approach in which the opportunity is built to generate hedged mega-balance and carry out hedged accounting iterations, evaluate the hedged potential of agribusiness, which, as has been said before, is of two types: hedged balance potential and market potential, depending on the assessment method. Moreover, the risk management 
methodology should cover the management of the reserve system as a way to protect agribusiness from the negative impact of factors of micro and macroeconomic origin.

The risk management process is associated with accounting identification of risk situations, determining the likelihood of adverse consequences, choosing protection methods and assessing their value, and making managerial decisions aimed at preserving the capital of agribusiness. In this regard, the adaptation of accounting should include monitoring indicators through which decisions are made. Monitoring is a process of permanent collection of all necessary information about the objects of management and the provision of its risk-managers. Information can be provided as often as required by the needs of the structural unit of risk management. An indicator is an analytical factor, the presentation interface of which is interconnected with the indicator process, i.e. by connecting with various level signals of a given indicator. For example, the yield indicator is associated with the formation of such an interface for providing the yield indicator, in which the manager sees its relationship with the breakeven point, at which you can immediately see whether the breakeven point is reached at a given crop size or not. The indicator provides information instantly without additional calculations. At the same time, it seems necessary for the risk management system to predict the risk of loss, and indicators associated with the breakeven point allow carrying out control functions regarding this situation.

Accounting should be directly interconnected with a decision support system, which in risk management is focused on decision making of the following type:

- positive decisions regarding the economic situation, when there is no risk or it is in the zone of maximum permissible values. In this case, a system of indicators signals the admissibility or feasibility of making this decision;

- positive decisions with protection are made regarding the economic situation when the risk value exceeds the maximum permissible value and protective measures are required in the form of risk insurance or reserve creation;

- amended decisions when information about a high degree of risk regarding the economic situation is received, and it is proposed to change approaches and methods for its implementation in order to reduce the risk exposure;

- negative decisions are recommended when the risk of a business transaction is high, protective mechanisms are unreasonable, since the costs of their implementation significantly exceed the economic effect of a committed business transaction, and there are no alternative options for this business transaction.

\section{Conclusion}

Thus, we can conclude that the proposed areas of accounting adaptation, based on the principles of adaptation, will create a holistic information system for decision support in accordance with the methodological recommendations for constructing a risk management system.

\section{References}

1. P. Shumilin, Naukovedenie, 3, 16 (2013) elibrary.ru/item.asp?id=20194817

2. M. Gunderson, M. Boehlje, M. Neves, S. Sonka, Encyclopedia of Agriculture and Food Systems, 51-70 (2014) DOI: 10.1016/B978-0-444-52512-3.00117-0

3. G. Behzadi, M. O’Sullivan, T. Olsen, A. Zhang, Omega, 79, 21-42 (2018) doi.org/10.1016/j.omega.2017.07.005 
4. E. Bornhofen, T. Ramires, T. Bergonci, et al., Agricultural Systems, 173, 281-288 (2019) doi.org/10.1016/j.agsy.2019.03.006

5. D. Zylbersztaj, Revista de Administração, 52, 1, 111-117 (2017) doi.org/10.1016/j.rausp.2016.10.004

6. J. Vinícius de Avila Pacheco, R. Morabito, Computers \& Industrial Engineering, 61, 3, 848-857 (2011) doi.org/10.1016/j.cie.2011.05.018

7. K. Boratyńska, E. Grzegorzewska, Journal of Business Research, 89, 175-181 (2018) doi.org/10.1016/j.jbusres.2018.01.028

8. T. Tyler, F. Thomas, Accounting, Organizations and Society, 53, 1-16 (2016) doi.org/10.1016/j.aos.2016.07.001

9. O. Vlismas, The International Journal of Accounting, 53, 4, 335-336 (2018) doi.org/10.1016/j.intacc.2018.11.005

10. A. Trigo, F. Belfo, R. Estébanez, Procedia Computer Science, 100, 987-994 (2016) doi.org/10.1016/j.procs.2016.09.264

11. D. Appelbaum, A. Kogan, M. Vasarhelyi, Z. Yan, International Journal of Accounting Information Systems, 25, 29-44 doi.org/10.1016/j.accinf.2017.03.003

12. D. Brysina, V. Tkach, Izvestiya of the Rostov State University of Civil Engineering, 2, 20, 102-108 (2015)

13. V. Eremenko, D. Yatsuk, Vector of Economics, 4, 10, 44 (2017) 